\title{
TURBULENT STRESS DISTRIBUTION IN THE TURBULENT BOUNDARY LAYER ON A PERMEABLE POROUS PLATE
}

\author{
D. Vlassovi ${ }^{a}$, J. V. C. Vargas ${ }^{a}$, J. C. \\ Ordonez $^{\text {b }}$ \\ and L. S. Martins ${ }^{a}$ \\ ${ }^{\mathrm{a}}$ Universidade Federal do Paraná \\ Departamento de Engenharia Mecânica \\ Centro Politécnico \\ Bairro Jardim das Américas \\ CP. 19011, Curitiba, Paraná, Brasil \\ vlassov@demec.ufpr.br \\ ${ }^{b}$ Department of Mechanical Engineering and Center for \\ Advanced Power Systems, \\ Florida State University, Tallahassee, FL 32310, USA
}

\begin{abstract}
In this paper the results of experimental tests on turbulent boundary layer on a plate with air blowing through permeable porous wall are presented. Tests were performed in an aerodynamic tunnel varying the blowing rate within the range of 0 to $2.5 \%$ of the air flow velocity in the tunnel, using thermoanemometers of constant temperature. It has been determined that the blowing increases the boundary layer thickness and strongly transforms the boundary layer inner part and turbulent nucleus, while the outer part remains not deformed. An increase in blowing causes an abrupt viscous stress decrease, also decreasing skin friction. Thick boundary layers (up to $120 \mathrm{~mm}$ ) allowed a profound analysis of Reynolds' turbulent stresses. It has been found a general distribution of turbulent stress in the turbulent layer which is independent of blowing velocity. It has been established for the turbulent characteristics that the determining coordinate is the relative horizontal velocity, not the distance from the wall. With a turbulent stress database obtained from turbulent stresses direct measurements, it has been proposed a flow model for boundary layer on a permeable porous plate. It has also been demonstrated that in high blowing conditions the horizontal velocity profile in the boundary layer becomes equal to the velocity profile in a plane jet.
\end{abstract}

Keywords: turbulent boundary layer, Reynolds' turbulent stresses, air blowing.

\section{NOMENCLATURE}

A coefficient for Eq. (14)

$a, b, c, d, e$ coefficients for Eq. (10)

$E$ thermo-anemometer output (voltage), $\mathrm{V}$

$e^{\prime} \quad$ Linearized thermo-anemometer floating output (voltage), $\mathrm{V}$

$K$ alcohol micro-manometer inclination coefficient

$k_{1}, k_{2}, k_{3}$ heat transfer related coefficients, Eqs. (5)

$\ell \quad(8)$

Mixed length, $\mathrm{m}$

$p \quad$ pressure, $\mathrm{Pa}$

$P \quad$ porosity, Eq. (1)

$R_{u^{\prime} v^{\prime}} \quad$ Correlation coefficient

$R e \quad$ Reynolds number based on plate length

$u^{\prime}, v^{\prime}, w^{\prime} \quad$ turbulent velocity components, $\mathrm{m} \mathrm{s}^{-1}$

$U, V \quad$ average velocity horizontal and vertical components, $\mathrm{ms}^{-1}$

$W \quad$ resulting average velocity in direction $\mathrm{z}, \mathrm{ms}^{-1}$

$x, y, z$

\section{Greek symbols}

$\beta \quad$ linearization coefficient

$\delta \quad$ boundarylayer thickness, $m$

$\zeta \quad$ argumentfor Eq. (15)

$\mu \quad$ dynamic viscosity, $N \mathrm{~s} \mathrm{~m}^{-2}$

$v \quad$ dynamic viscosity, $\mathrm{m}^{2} / \mathrm{s}$

$\rho \quad$ density, $\mathrm{kg} \mathrm{m}^{-3}$

$\tau \quad$ tangential stress, $P a$

$\varphi \quad$ angle between the velocity vector and the wall, ${ }^{\circ}$

\section{Subscripts}

c stainless steel

$\max$ maximum

\author{
porous material \\ turbulent \\ wall \\ free stream conditions \\ perpendicular to the sheet horizontal axis \\ parallel to the sheet horizontal axis \\ viscous \\ friction dynamic \\ parameter without blowing
}

\section{Superscript}

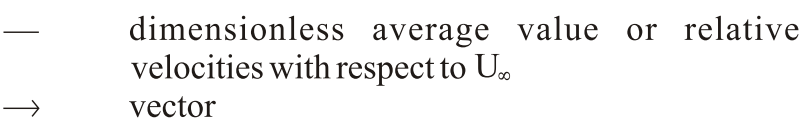

\section{INTRODUCTION}

The injection or suction of a fluid through permeable walls aiming to control the boundary layer development has captured the attention of scientists and engineers for a fairly long time (e.g. Schlichting, 1960; Kays, 1972). Due to their high efficiency as boundary layer control mechanisms, they are still of interest for applications as well as for the characterization of the physical mechanisms involved in boundary layer development (Bushnell and Hefner, 1990; El-Hady, 1991; Antonia and Zhu, 1995; Vilela-Mendes and Dente, 1997; Bellettre et al., 1999a; Bataille

Some of the practical problems in which fluid blowing is used are the thermal protection ("transpiration" method) of surfaces exposed to high amounts of enthalpy flows (gas turbine blades, combustion chamber walls and other rocket engine parts), the superficial friction decrease of airplanes, ships and wings and the lift increase of aircraft (e.g. Silva Freire et al., 1995; Bellettre, et. al., 1997; Rodet et al., 1997.; Bellettre et al., 1999b). 
In case of thermal protection, the establishment of a transpiration flow through permeable wall allows the wall temperature control at a specific level to keep it working safely (e.g., Bellettre et al., 1999b; Bellettre et al., 2000; Polyakov et al., 2001). Previous studies have shown significant skin-friction reductions at the permeable wall (e.g., Hahn and Choi, 2002). The economic performance of this method depends on the way the transpiration flow is supplied to the surface. The most economic method seems to be the one in which the transpiration flow is supplied through a porous wall.

Even if one considers the simplest conditions (isothermal boundary layer, no horizontal pressure gradient, uniform blowing, etc.) the turbulent boundary layer equations system is not closed due to lack of knowledge about Reynolds' turbulent stresses. To close the system of equations several hypotheses are considered that generally set a correlation between the Reynolds' turbulent stresses and average horizontal velocity on the boundary layer. However, among hundreds of hypotheses, it has not been found a general one that would fit to the whole boundary layer and this is the reason experimental research on turbulent boundary layer properties is indispensable. Measurement methods of Reynolds' turbulent stress in the boundary layer (laser anemometers and hot wire) have faced difficulties related to boundary layers low thickness, high velocity gradients near wall and wall presence influence.

Turbulent stresses exert a major influence on the average velocity profile in the boundary layer formation. Measurements data taken in the boundary layer on a impermeable sheet support the existence of a turbulent stress maximum near the wall. The decrease of turbulent stress on the boundary layer outer part was studied by several authors (e.g., Schwarz et al., 2002), but their "behavior" towards the wall is yet to be defined (e.g., Metzger et al., 2001). However, it is known fluid blowing in the boundary layer, through permeable wall reduces abruptly the velocity gradient near the wall and leads to an enlargement of the low velocity values zone, which allows the researcher to study profoundly the essence of formation and development of turbulent stresses in the vicinities of the wall.

The development of a theory on boundary layer control using fluid blowing through porous walls, the elaboration of precise mathematical models, and the numerical simulation of flows in the turbulent boundary layer require profound knowledge of energy and mass turbulent transport phenomena. The present paper main objective is to study theoretically and experimentally turbulent boundary layer transformation patterns on porous planes aiming to develop a general correlation for turbulent stresses in closed analytical form.

\section{EXPERIMENTAL MODEL, FLOW PARAMETER AND EQUIPMENTS}

The model is a plate of $2.53 \mathrm{~m}$ total length and $0.4 \mathrm{~m}$ width. The plate consisted of a front impermeable segment of $1 \mathrm{~m}$, a porous permeable segment of $1.03 \mathrm{~m}$ and a rear segment of $0.5 \mathrm{~m}$. The front segment length was designed to assure a developed turbulent boundary layer in the beginning of the permeable segment, $\operatorname{Re} \approx 6.5 \times 10^{5}$, and the rear segment length was calculated to avoid the influence of separation of the boundary layer on the porous segment.
The porous sheet was manufactured by a hot forming process in vacuum media using stainless steel meshes. The porous sheet thickness was $7.75 \mathrm{~mm}$, the porosity $11.8 \%$. The porous diameter average value was $15 \mu \mathrm{m}$. Air blowing was measured by means of a micro flow rate meter based on a thermo-anemometer. Air blowing variation was within $10 \%$. In the middle of the plate, where measurements were taken, air blowing variation was within $5 \%$.

The porosity of the plate material was calculated by:

$$
P=\frac{\rho_{c}-\rho_{p}}{\rho_{c}}
$$

where $\rho_{c}$ is the stainless steel density from which the grid wires were made, $\mathrm{kg} / \mathrm{m}^{3}$, and $\rho_{p}$ is the porous material density, $\mathrm{kg} / \mathrm{m}^{3}$.

The experimental research was performed in a subsonic A-10 aerodynamic tunnel, equipped with an Eiffel chamber at Moscow High Technical School Named Bauman, MHTS, Russia. The experimental rig is shown schematically in Fig. 1. The tunnel is made from wood and the Eiffel chamber from steel. A flow straightener was placed at the tunnel entrance, consisting of a cells arrangement (honeycomb) to make the flow as uniform as possible. The nozzle area reduction was reduced around 15 times. The test chamber consisted of a regular octagon with distances among walls of $800 \mathrm{~mm}$ and length of $1750 \mathrm{~mm}$. The air flow was created with a 12-blade fan place at the diffuser outlet. The fan was powered by an alternate current electric motor. The electromagnetic glove was used to control the fan speed. To avoid the influence on fan speed from casual electric voltage and temperature variation, an electronic control system with a tachometer and reaction coupling was implemented. During the experimental runs, with the help of that system, the fan speed was kept constant, to insure a constant air speed in the test chamber.

The air flow parameters were as follows: air free stream velocity $\mathrm{U}_{\infty}=10 \mathrm{~m} / \mathrm{s}(0.5 \%)$; turbulence rate at nozzle exit $0.5 \%$; at diffuser entrance $0.7 \%$; air temperature $\sim 20^{\circ} \mathrm{C}$; pressure gradient in the test chamber was $\cdot \frac{d p}{d x} \cong 0$

The insufflated air velocity through the porous wall had seven discrete values $\mathrm{V}_{\mathrm{w}}=0$ (no blowing); $0.05 ; 0.1$; $0.142,0.18 ; 0.212$ and $0.243 \mathrm{~m} / \mathrm{s}$, where: $\mathrm{V}_{\mathrm{w}}$ - normal velocity component, the subscript $\mathrm{w}$ indicates a parameter value at the wall. The experimental conditions were isothermal, since both the tunnel and the transpiration air had the same temperature.

The measurements of the boundary layer parameters were performed using experimental equipment made in Denmark by the company DISA.
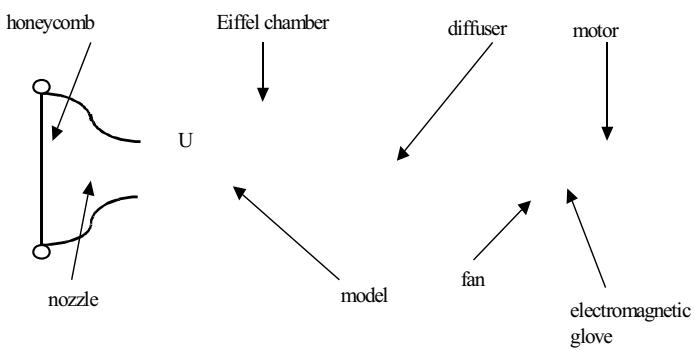

Figure 1. Experimental rig schematic diagram (model and wind tunnel). 
The following devices were utilized: 4 thermoanemometers 55D01; 2 current linearizers 55D10 (to obtain a thermo-anemometer linear output); filters 55D25; DC voltmeters 55D30; AC voltmeters 55D35; 1 analog correlation coefficient meter 55A06; 1 wind tunnel 55D41/42 for the calibration of the thermo-anemometers wires; 4 hot wire transducers 55A22, with wire length and diameter of $1.2 \mathrm{~mm}$ and $0.005 \mathrm{~mm}$, respectively (it was made from tungsten and covered with a platinum layer to prevent corrosion.), and 2 "X" shaped hot wire transducers $55 \mathrm{~A} 38$, with length and diameter of $1 \mathrm{~mm}$ and $0.005 \mathrm{~mm}$, respectively. The frequency response of the system is of $400 \mathrm{kHz}$.

In order to perform the measurements and to produce velocity turbulent components oscillograms, the following devices were utilized: a summer and subtraction block, a 20-channel electromagnetic recorder with frequency modulation, manufactured by URAN, for the continuous recording and data treatment of measured parameters, a 2-channel cathodic oscilloscope C1-19B with a photo camera, and alcohol micro-manometers with an inclination coefficient $\mathrm{k}=0.05$.

To move the transducers in the boundary layer a special coordinating mechanism with remote control was used. The mechanism had two degrees of freedom for vertical translation (along the vertical axis y and around it). The linear and angular bias limits were $0.01 \mathrm{~mm}$ and $0.1^{\circ}$, respectively. The transducer distance from the wall to the plate was measured with an optic cathetometer with a bias limit of $0.001 \mathrm{~mm}$ and focal distance of $650 \mathrm{~mm}$.

\section{METHODOLOGY}

\section{Average velocity components determination}

In the boundary layer on the porous permeable plate, with blowing, an accentuated curvature in the streamlines is observed. Right on the wall, the velocity vector $\overrightarrow{\mathrm{W}}_{\mathrm{w}}$ is driven by the wall surface normal vector and its magnitude is numerically equal to the blowing velocity $\mathrm{V}_{\mathrm{w}}$, because at the wall $\mathrm{W}_{\mathrm{w}}=\mathrm{V}_{\mathrm{w}}$. As the distance from the wall increases the streamlines bend and the angle between the velocity vector and the wall, $\varphi$, diminishes. At the external edge of the boundary layer, the velocity vertical component is null, $\mathrm{V}_{\infty}=0$ and the velocity becomes equal to the free stream velocity, $\mathrm{W}=\mathrm{U}_{\infty}$ (the infinity subscript is used to indicate a parameter outside the boundary layer). To calculate the velocity horizontal and vertical components $\mathrm{U}(\mathrm{y})$ and $\mathrm{V}(\mathrm{y})$ is therefore necessary to know $\overrightarrow{\mathrm{W}}(\mathrm{y})$.

To decompose the velocity vector into components $\mathrm{U}$ and $\mathrm{V}$ a special methodology was devised (Vlassov, $1975,2002)$. The phenomenon of heat transfer variation between the thermo-anemometer wire and the air as a function of the wire position with respect to the velocity vector $\mathrm{W}$ was used. The thermo-anemometer wire was calibrated in a special air tunnel as a function of the velocity variation and the angle. Based on the calibration results, a graph was drawn, $E=f(W, \varphi)$, where: $E$ - thermoanemometer output (voltage), in Volts.

During the test, the sensor was mounted at a point in the boundary layer at two positions, as shown in Fig. 2: position a) perpendicular to the sheet horizontal axis $\mathrm{x}$; position b) parallel to the same axis. Two values from the thermo-anemometer were recorded $\mathrm{E}$ and $\mathrm{E}$. The values of $\mathrm{W}$ and $\varphi$ were determined using the calibration chart.
The velocity vector components were calculated as $\mathrm{U}=\mathrm{W} \cos \varphi$ and $\mathrm{V}=\mathrm{W} \cdot \sin \varphi$.

\section{Turbulent stresses determination}

The total tangential stress (shear) in the boundary layer consists of viscous and turbulent stresses

$$
\tau=\tau_{v}+\tau_{t}=\mu \frac{d U}{d y}-\rho \overline{u^{\prime} v^{\prime}}
$$

where $\tau$ is the total tangential stress; $\tau_{v}$ the viscous tangential stress; $\tau_{t}$ the turbulent tangential stress; $\mu$ the dynamic viscosity; $\rho$ density, and $\overline{u^{\prime} v^{\prime}}$ mean value of the instantaneous product of the horizontal and vertical turbulent components (corresponding to) of velocity.

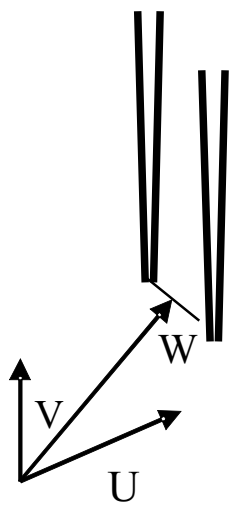

a)

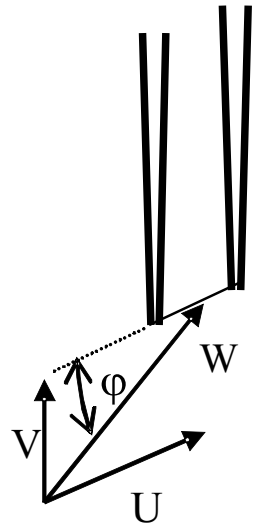

b)

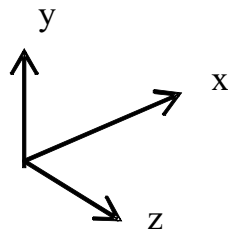

Z
Figure 2. Thermo anemometers positions: a) perpendicular to the sheet horizontal axis $\mathrm{x}$; b) parallel to the same axis.

The viscous stresses $\tau_{v}$ are determined from the average horizontal velocity profile $U$ in the boundary layer and the turbulent stresses $\tau_{\mathrm{t}}$ are a result of the inertial interaction and non-linear velocity pulsations.

A well established method and tested in practice, of turbulent stresses determination is based on the following formula (Hinze, 1975)

$$
\tau_{t}=\rho \overline{u^{\prime} v^{\prime}}=\rho R_{u^{\prime} v^{\prime}} \sqrt{\overline{u^{\prime 2}}} \sqrt{\overline{v^{\prime 2}}}
$$

where $\sqrt{\overline{u^{\prime 2}}}$ is the intensity (dispersion) of the turbulent horizontal component; $\sqrt{\overline{v^{\prime 2}}}$ the intensity (dispersion) of the turbulent vertical component, and $R_{u^{\prime} v^{\prime}}$ a correlation coefficient.

A well known method of velocity turbulent components measurement is based on the use of two thermo-anemometers and one thermo-anemometric transducer in cross, as shown in Fig. 3, which was proposed by Hinze (1975). During the measurement of velocity turbulent components $\mathrm{u}^{\prime}$ and $\mathrm{v}$; it is generally considered that the wires should be on a vertical plane $\mathrm{x} 0 \mathrm{y}$ and the transducer axis in cross should coincide with the horizontal velocity component. In this case, the linearized thermo-anemometer floating outputs are the following:

$$
e_{1}^{\prime}=\frac{\beta}{\sqrt{2}}\left(u^{\prime}+v^{\prime}\right) \text { and } e_{2}^{\prime}=\frac{\beta}{\sqrt{2}}\left(u^{\prime}-v^{\prime}\right)
$$


where $e_{1}^{\prime}$ and $e_{2}^{\prime}$ are the linearized thermo-anemometer floating outputs (voltage), in Volts, and $\beta$ the linearization coefficients.

The sum of $\mathrm{e}_{1}^{\prime}+\mathrm{e}_{2}^{\prime}$ is proportional to $\mathrm{u}^{\prime}$, and the difference is proportional to $v^{\prime}$. The values of $\sqrt{\overline{u^{\prime 2}}}$ and $\sqrt{\overline{v^{\prime 2}}}$ of Eq. (3). In the boundary layer, the correlation were determined after separation of the components.

The turbulent stresses were then determined by coefficient varied within the range $-0.42<R_{u^{\prime} v^{\prime}} \leq 0$ On the wall, the velocity pulsations are null and the correlation coefficient equals to zero, $R_{u^{\prime} v^{\prime}}=0$, while moving farther from the wall, the correlation coefficient decreases to the minimum value -0.42 .

At the boundary layer external edge, it is equal to zero. The negative sign of the correlation coefficient indicates that the horizontal and vertical instantaneous mean values of the turbulent components vary contrarily. The correlation coefficient measurements showed that it varies only as a function of the relative velocity $\bar{U}=\frac{U}{U_{\infty}}$. A blowing parameter is also defined as $\overline{V_{w}}=\frac{V_{w}}{U_{\infty}}$. The blowing intensity had a small influence on the correlation coefficient. The turbulent boundary layer flow is characterized by the average velocity vector $\overrightarrow{\mathrm{W}}$ located under a $\varphi$ angle with respect to the transducer axis (the " $X$ " shaped thermo-anemometer 55A38 transducer axis is parallel to the plane, wall). The velocities field is characterized by the average velocities $\mathrm{U}$ and $\mathrm{V}$, and turbulent components $\mathrm{u}, \mathrm{v}$ and $\mathrm{w}$ corresponding to the axes $\mathrm{x}, \mathrm{y}$ and $\mathrm{z}$, respectively, as it is shown in Fig. 3 .

If the wires characteristics are linearized and their sensibilities are equal, the cooling effective wire velocities are determined by:

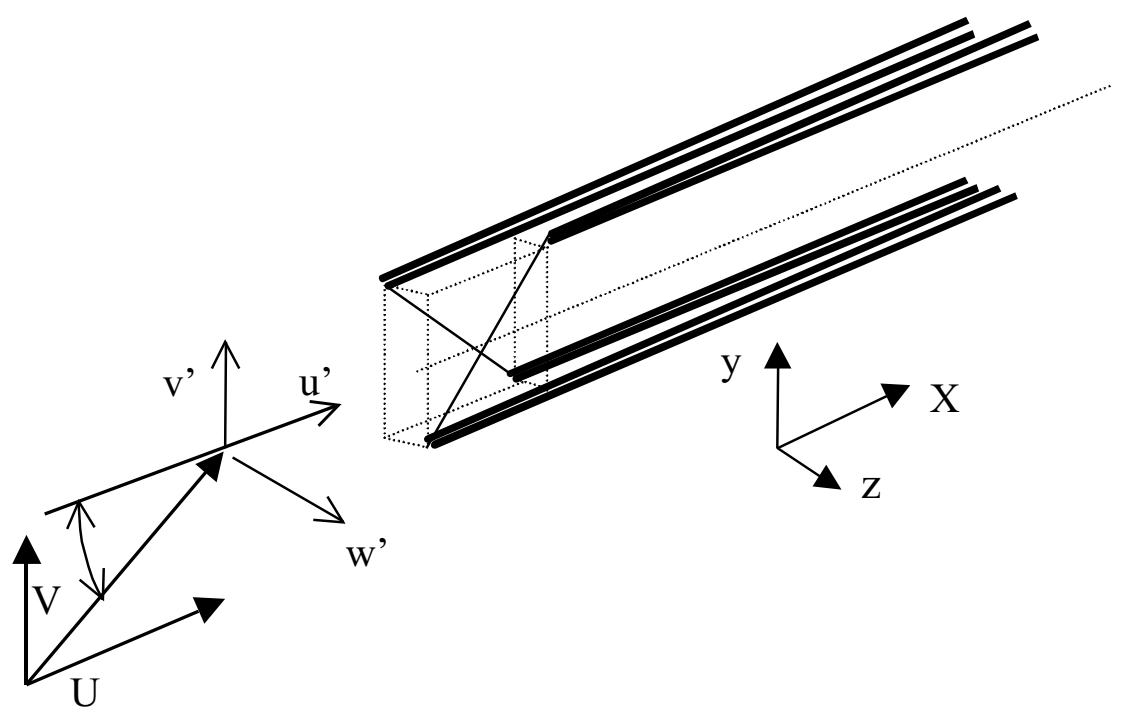

Figure 3. Positioning of two thermo-anemometers and one thermo-anemometric transducer 55A38 in cross (Hinze, 1975).

$$
\begin{aligned}
& \left|U_{1}\right|=\sqrt{\frac{k_{1}^{2}\left(U+u^{\prime}+V+v^{\prime}\right)^{2}+k_{2}^{2}\left(U+u^{\prime}-V-v^{\prime}\right)^{2}+k_{3}^{2} w^{\prime 2}}{2}} \\
& \left|U_{2}\right|=\sqrt{\frac{k_{1}^{2}\left(U+u^{\prime}-V-v^{\prime}\right)^{2}+k_{2}^{2}\left(U+u^{\prime}+V+v^{\prime}\right)^{2}+k_{3}^{2} w^{\prime 2}}{2}}
\end{aligned}
$$

In Equations (5) and (6), $\mathrm{k}_{1}, \mathrm{k}_{2}$ and $\mathrm{k}_{3}$ are coefficients that take into account the fluid flow and heat transfer conditions close to the wire in directions $\mathrm{x}, \mathrm{y}$ and $\mathrm{z}$. The numerical values of those coefficients depend on several factors. Particularly, they depend on the wire length-diameter relation, the velocity, dimensions and needles shapes and wire supports. To determine the numerical values of those coefficients, supplementary wire calibrations were performed for different angles with respect to the flow direction. Considering $\mathrm{k}_{1}=1$, for the probe $55 \mathrm{~A} 38$ and for flow velocities from 0 to $10 \mathrm{~m} / \mathrm{s}$, the coefficients numerical values are approximately determined as $k_{2} \approx 0.25$ and $k_{3} \approx 1.22$.

Transforming Eqs. (5) and (6) and taking the pulsations sum and difference, $u^{\prime}$ and $v^{\prime}$, it is obtained:

$$
u^{\prime}+v^{\prime}=\frac{\sqrt{2}}{\beta}\left(e_{1}^{\prime}-k_{2}^{2} e_{2}^{\prime}\right) \sqrt{1+k_{2}^{2} \operatorname{tg}\left(\frac{\pi}{4}-\varphi\right)}
$$

$$
u^{\prime}-v^{\prime}=\frac{\sqrt{2}}{\beta}\left(e_{2}^{\prime}-k_{2}^{2} e_{1}^{\prime}\right) \sqrt{1+k_{2}^{2} \operatorname{ctg}\left(\frac{\pi}{4}-\varphi\right)}
$$

Equations (7) and (8) transform into Eqs. (4) when the angle between the average velocity horizontal and vertical components is zero, $\varphi=0$ and $k_{2}<<1$. Note that for $k_{2}=0.25$, when $e_{1}^{\prime} \approx e_{2}^{\prime}$ and $\varphi=0$, the first Eq. (4) is correct with an error of $1.62 \%$, and the second Eq. (4) has na error of $4.46 \%$. Equations ( 7 ) and (8) allow for the evaluation of the influence of the angle $\varphi$ on the accuracy of the measurement of the components $u^{\prime}$ and $v^{\prime}$, using Eqs. (4). As $\varphi$ increases the accuracy of the first Eq. (4) decreases and when $\varphi=35^{\circ}$, the error increases up to $5 \%$.

The accuracy of the second Eq. (4) behaves in an opposite way, as $\varphi$ increases, the accuracy increases, and when $\varphi=$ $35^{\circ}$, the error approaches $0 \%$. As the accuracy of one decreases and of the other increases, the total accuracy becomes almost constant, $\approx 5 \%$, and within the range $0 \leq \varphi \leq 35^{\circ}$ does not depend on the angle $\varphi$. In the present work, during the measurements of the boundary layer turbulent characteristics in a section, the axis of the probe 55A38 was always in parallel to the wall, changing its position in the axis $y$, and to determine the velocities turbulent components, Eqs. (4) were used. The starting distance from the probe 55A 38 to the wall was measured 
using a cathetometer, as the distance from the wires crossing to the wall. It is obvious that on the error in the turbulent components measurements, the velocity gradient $\frac{d U}{d y} \quad$ still influences. The distance between needles (supports) of a wire of the probe 55A38 is approximately $0.7 \mathrm{~mm}$. In the present work, in the case of a boundary layer without transpiration, in the interval $0 \leq y \leq 0.7 \mathrm{~mm}$ from the wall, the relative velocity $\bar{U}$ varies from 0 at the wall up to the value $\bar{U} \approx 0.6$. Table 1 shows the measured values of $U$ in the section $\mathrm{x}=700 \mathrm{~mm}$ from the start of the porous part of the plate, at a distance $y=0.7 \mathrm{~mm}$ from the wall. The data presented in Table 1 reveal that even at that small distance from the wall, the velocity gradient abruptly decreases as the blowing parameter increases. That fact eliminates the influence of the velocity gradient $\frac{d U}{d y}$ on the turbulent components and increases the accuracy of their measurements.

Table 1 Measured values of $U$ at $x=700 \mathrm{~mm}$ and $\mathrm{y}=$ $0.7 \mathrm{~mm}$.

\begin{tabular}{|c|c|c|c|c|c|c|}
\hline $\bar{V}_{W}$ & 0 & 0.005 & 0.01 & 0.0142 & 0.018 & 0.0212 \\
\hline $\mathrm{U}(\mathrm{m} / \mathrm{s})$ & 0.6 & 0.33 & 0.19 & 0.06 & 0.02 & 0.01 \\
\hline
\end{tabular}

Another measurement method of turbulent stresses is to obtain directly the electric sign proportional to $\mathrm{u} \mathrm{X} \mathrm{v}=$ $\frac{\mathrm{u}^{\prime} \mathrm{v}^{\prime}}{\mathrm{u}^{\prime} \mathrm{v}^{\prime}} \quad$ and in the determination of the average value of. For that, Eqs. (4) were raised to the square power and the difference $e_{1}^{2}-e_{2}^{2}=\frac{\beta^{2}}{2} 4 u^{\prime} v^{\prime} \quad$ [or $\left.u^{\prime} v^{\prime}=\frac{1}{2 \beta^{2}}\left(e_{1}^{2}-e_{2}^{2}\right)\right]$ was determined. The instantaneous product average value was then determined from the readings of a DC voltmeter.

$$
\overline{u^{\prime} v^{\prime}}=\frac{\overline{e_{1}^{2}-e_{2}^{2}}}{2 \beta^{2}}
$$

In the present study, both turbulent stresses determination methods were used. The determination of $\tau_{t}$ was accomplished through Eqs. (3) and (4). The second method determined $\tau_{t}=-\rho \overline{u^{\prime} v^{\prime}}$ directly with Eq. (9). Both methods showed similar results. The second one is preferential because it does not require a coordinating mechanism to evaluate the correlation coefficient.

\section{RESULTS AND DISCUSSION}

\section{Average velocity profiles}

Velocities profiles on a porous plate were measured in 5 sections along the plate length: 100, 300, 500, 700 and $900 \mathrm{~mm}$ from the start of the permeable porous sector. In all sections, it was detected a strong deformation of the average velocities profiles caused by transpiration. In Figure 4, the dimensionless average velocity horizontal component profiles, $\bar{U}=f(y)$, are shown at a distance of

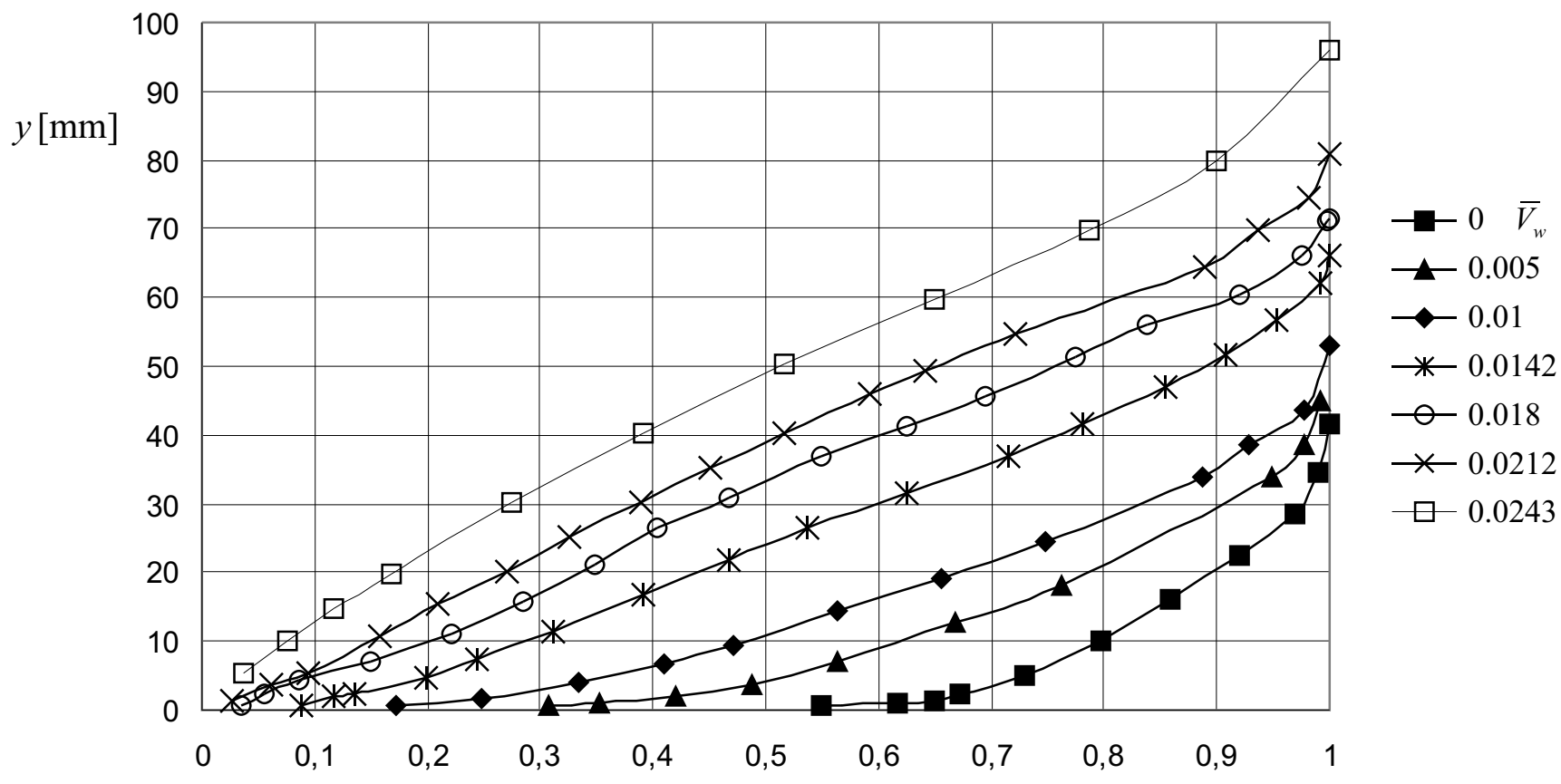

Figure 4. Average horizontal velocity component profiles at $\mathrm{x}=700 \mathrm{~mm}$. 


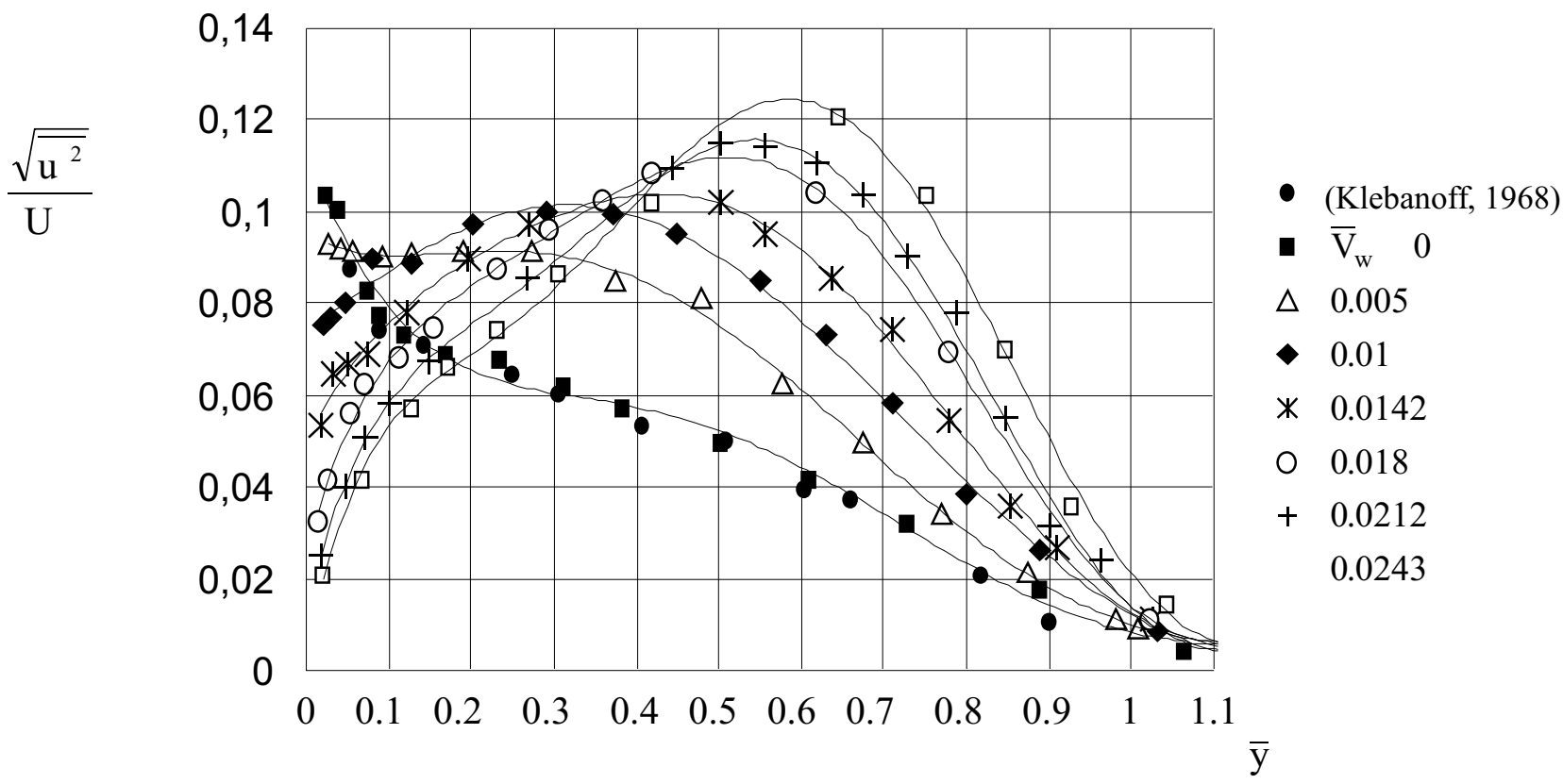

Figure 5. Horizontal velocity turbulent component intensity distribution with respect to boundary layer thickness, for several values of the blowing parameter at $\mathrm{x}=700 \mathrm{~mm}$.

$700 \mathrm{~mm}$ from the start of the porous sector of the plate. The transpiration causes a rapid growth of the thickness of the boundary layer, which by the end of the porous sector $(\mathrm{x}=$ $1030 \mathrm{~mm})$ reached a thickness $\delta=130 \mathrm{~mm}\left(\bar{V}_{W}=0.0243\right)$. The thickness of the boundary layer was determined through the usual criterion $\delta=\left.y\right|_{\bar{U}=099^{\circ}}$

High boundary layer thicknesses induced by blowing allowed for deeper instrumental investigations of their properties. Note that the transpiration influence on the thickness of the boundary layer exists not only on the porous plate, but also in the leading and trailing edges of the model.

As the transpiration increases, in the entire boundary layer zone the deformation increases. As the blowing velocity increases, the velocity gradient at the wall, $\frac{\mathrm{dU}}{\mathrm{dy}}$,

abruptly decreases. In the internal boundary layer zone, velocity profiles are formed with sections of constant velocity gradients. It is observed that, in the external part of the boundary layer, the velocity variation $\bar{U}=f(y)$ does not depend on the blowing velocity. The thickness of the boundary layer internal zone increases as $\mathrm{x}$ increases. The influence of the blowing has an integral character as $\mathrm{x}$ increases.

The measurements of the velocity profiles, $U=f(y)$, close to the porous plate surface, showed that as the blowing parameter, $\bar{V}_{w}$, increases, the viscous sub-layer increases rapidly. At the viscous sub-layer, linear profiles of the horizontal velocity component, $U=f(y)$, continue to exist. Under large values of the blowing parameter, the thickness of the viscous sub-layer reached values of several milimeters. The existence of a linear profile of the velocity $U$ at the wall allowed the determination of the

viscous stress, $\tau_{w}=\mu \frac{d U}{d y}$, and local frictionco efficients. investigated values of the blowing parameter, it was determined that, at the viscous sub-layer, the linear behavior of the profile of the horizontal velocity component continues up to the value of the dimensionless coordinate, $y^{+}=\frac{y U_{\tau}}{v} \approx 5$ where $\mathrm{U}_{\tau}$ is the friction dynamic velocity $U_{\tau}=\sqrt{v \frac{d U}{d y}} \quad$, and is the kinematic
viscosity.

\section{Velocity turbulent components}

In Figures 5 and 6, measurement results of the velocity turbulent components are shown, horizontal $\frac{\sqrt{u^{\prime 2}}}{U_{\infty}}$ and vertical $\frac{\sqrt{v^{\prime 2}}}{U_{\infty}}$, respectively, as functions of the boundary layer dimensionless thickness for different values of the blowing parameter. In the impermeable plate case, the measured results are in good agreement with previous reported measurements (Klebanoff, 1968). It is important to note that the horizontal pulsations have a sharp maximum very close to the wall, while the vertical component maximum is smoother and located a little farther from the wall. From those observations it is concluded that, in the turbulence generation zone, the vortices shape is more elongated in the horizontal direction. Moving away from the wall the velocity components intensity becomes less anisotropic. The transpiration greatly affects the turbulence distribution in the boundary layer. The curves maxima of the pulsations intensities become smoother and located even farther from the wall. With large blowing values, the pulsations maxima for $\frac{\sqrt{\overline{u^{\prime 2}}}}{U_{\infty}}$ and $\frac{\sqrt{v^{\prime 2}}}{U_{\infty}}$ are practically at the same distance from the wall.

For several sections of the porous plate, and for all 
Figures $7 \mathrm{a}$ and $7 \mathrm{~b}$ show the oscillograms of the horizontal and vertical components, $\mathrm{u}$ and $\mathrm{v}$, as functions of time. In the viscous sub-layer there is an intermittence character, since the turbulent flow alternates with the laminar flow. The intermittence zone increases as the blowing velocity increases. The growth of the thickness of the viscous sub-layer as the blowing velocity increases causes the pulsations to have thecharacteristic frequency of low pulsations, with large anisotropy
(Fig. $7 \mathrm{a}, \mathrm{y}=6.5 \mathrm{~mm}$ ). It is possible to observe the same effect in Fig. 7b, where oscillograms of the velocity components are recorded at the same distance from the porous wall, $\mathrm{y}=1.5 \mathrm{~mm}$, with respect to the variation of the blowing velocity.

In the oscillograms, it is possible to observe that near the wall, the air blowing in the boundary layer reduces the amplitude and frequency of the pulsations.

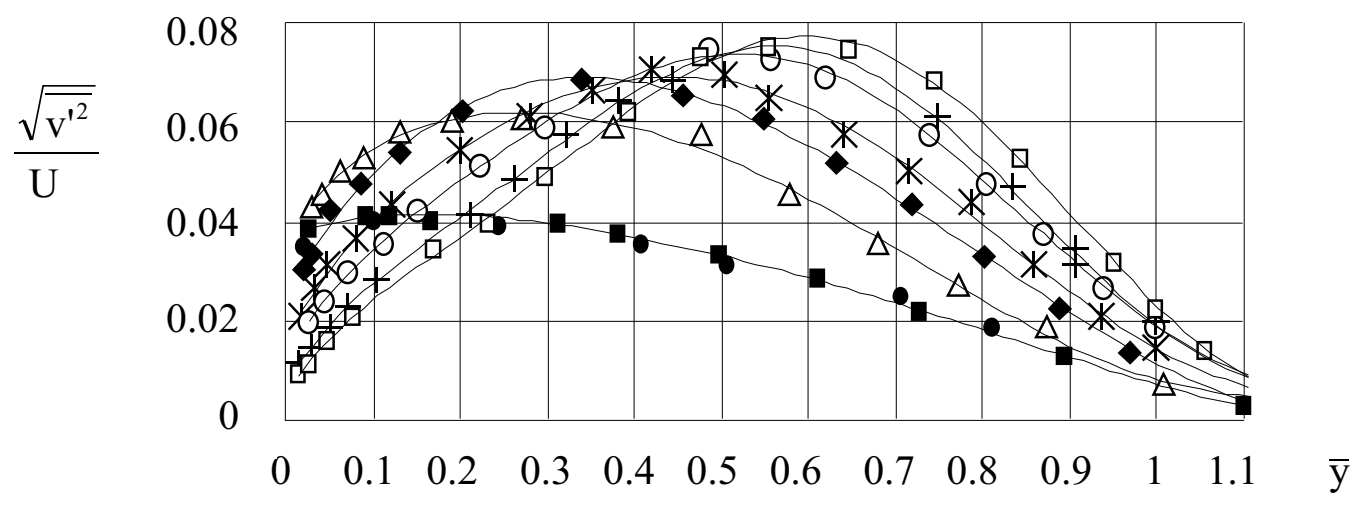

Figure 6. Vertical velocity turbulent component intensity distribution with respect to boundary layer thickness, for several values of the blowing parameter at $\mathrm{x}=700 \mathrm{~mm}$ (same legend as in Fig. 5).

The anisotropy of the velocity turbulent components is a direct result of the average velocity gradient near the wall. The square-averaged values of the velocity pulsations components $\sqrt{\overline{u^{\prime 2}}}$ and $\sqrt{\overline{v^{\prime 2}}}$ could be treated as square-average dispersions of the random functions. Because of that, the ratio between the squareaveraged values of the velocity components pulsations $\sqrt{\overline{u^{\prime 2}}}$ and $\sqrt{\overline{v^{\prime 2}}}$ could be treated as an anisotropic coefficient, $k=\frac{\sqrt{\overline{u^{\prime 2}}}}{\sqrt{\overline{v^{\prime 2}}}}$. The calculation of the anisotropic coefficient showed that it varies from 2.2 near the wall, down to 1 in the external part of the boundary layer.

Qualitatively, the anisotropy of the velocity turbulent components, $\mathrm{u}^{\prime}$ and $\mathrm{v}^{\prime}$, is observed in Fig. 7a. Near the wall, the amplitude of $u^{\prime}$ is always larger than of v'. Moving to the external part of the boundary layer, the velocity turbulent components become equal, and the turbulence becomes isotropic.

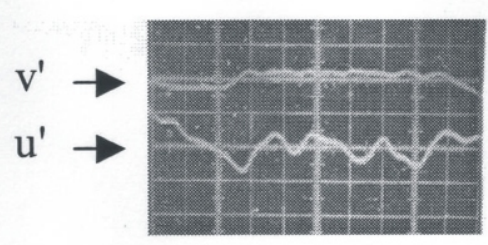

$\mathrm{y}=6.5 \mathrm{~mm}$

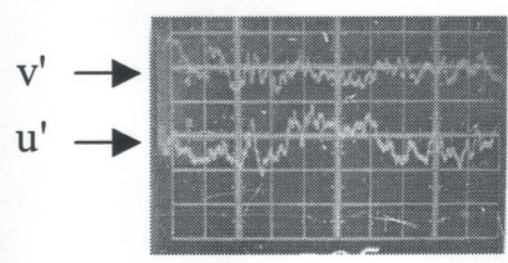

$\mathrm{y}=71.5 \mathrm{~mm}$

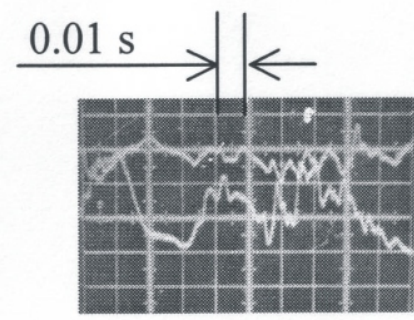

$\mathrm{y}=21.5 \mathrm{~mm}$

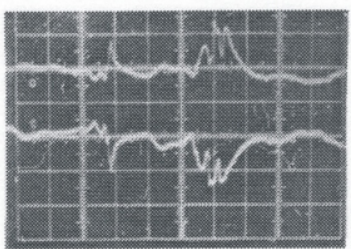

$\mathrm{y}=96.5 \mathrm{~mm}$

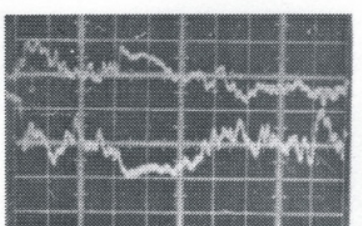

$\mathrm{y}=41.5 \mathrm{~mm}$

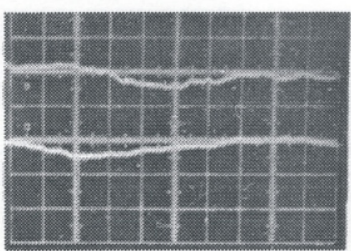

$\mathrm{y}=111.5 \mathrm{~mm}$

(a) 


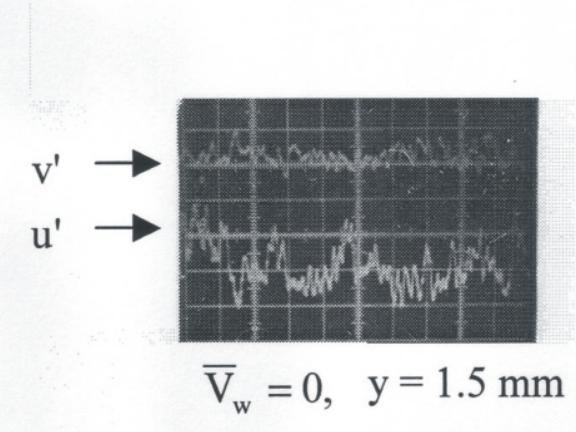

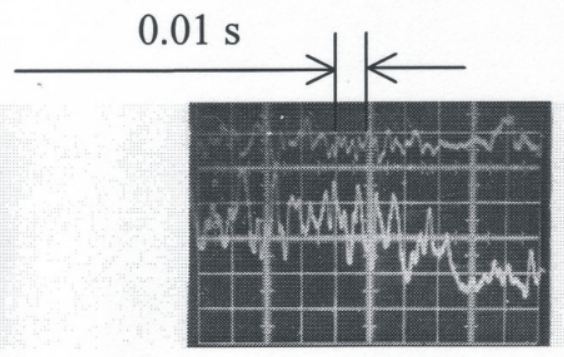

$\overline{\mathrm{V}}_{\mathrm{w}}=0.01, \mathrm{y}=1.5 \mathrm{~mm}$

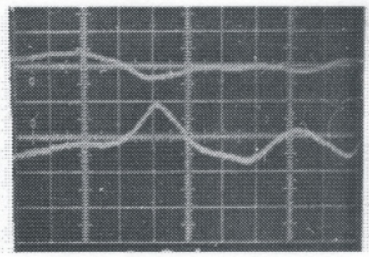

$\overline{\mathrm{V}}_{\mathrm{w}}=0.0243, \mathrm{y}=1.5 \mathrm{~mm}$

(b)

Figure 7. (a) Oscillograms of the horizontal $\frac{\sqrt{\overline{u^{\prime 2}}}}{U_{\infty}}$ and vertical $\frac{\sqrt{\overline{v^{\prime 2}}}}{U_{\infty}}$ velocity turbulent components with respect to boundary layer thickness $\left(x=700 \mathrm{~mm}, \overline{\mathrm{V}}_{\mathrm{w}}=0.0243, \delta=98 \mathrm{~mm}\right)$; (b) Oscillograms of the horizontal $\frac{\sqrt{\overline{u^{\prime 2}}}}{U_{\infty}}$ and vertical $\frac{\sqrt{\overline{v^{\prime 2}}}}{U_{\infty}}$ velocity turbulent components for different values of the blowing parameter $(x=700 \mathrm{~mm}, y=1.5 \mathrm{~mm})$

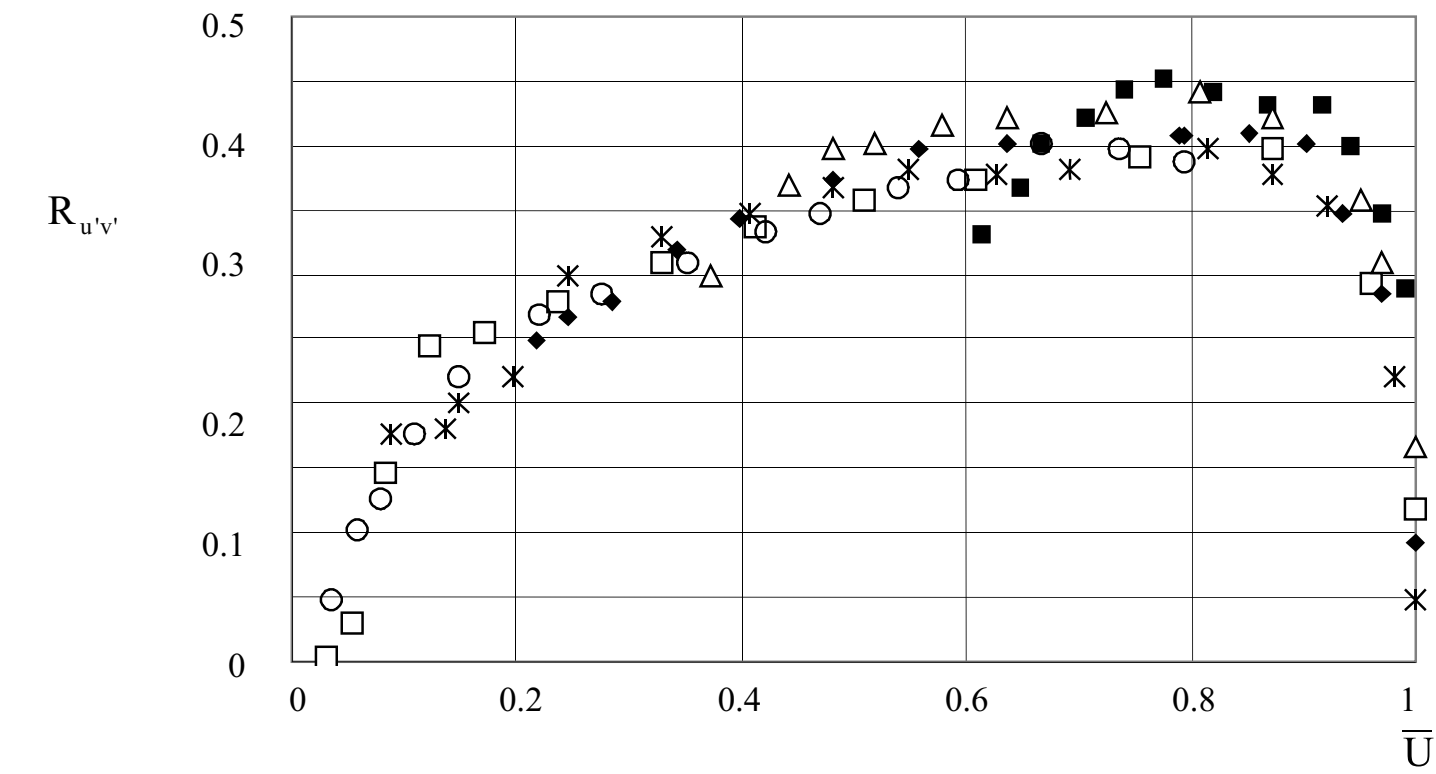

Figure 8. Correlation coefficient variation with respect to dimensionless average horizontal velocity at $\mathrm{x}=700 \mathrm{~mm}$ (same legend as in Fig. 5).

\section{Turbulent stresses}

The turbulent stresses were determined through Eq. (3). The measurements of the correlation coefficient showed that, in the boundary layer, independently of the blowing parameter, $\bar{V}_{w}$, the variation was approximately in the range $-0.42<R_{u^{\prime} v^{\prime}} \leq 0$. It is assumed that, at the wall, the velocity pulsations are null, and for the correlation coefficient it was assigned the value zero, $R_{u^{\prime} v^{\prime}}=0$. As the distance from the wall increases, the correlation coefficient decreases from zero down to the minimum value -0.42 . In the external part of the boundary layer, the correlation coefficient becomes zero again. The negative sign of the correlation coefficient indicates that the instantaneous values of the horizontal and vertical velocity turbulent components almost always vary in anti-phase. sign of the correlation coefficient indicates that the instantaneous values of the horizontal and vertical velocity turbulent components almost always vary in anti-phase.

In all oscillograms shown in Figs $7 \mathrm{a}$ and $7 \mathrm{~b}$, it could be seen that the components $\mathrm{u}^{\prime}$ and $\mathrm{v}^{\prime}$ are in anti-phase, causing the negative sign of the correlation coefficient, therefore the negative sign of the instantaneous product of those components in the turbulent stresses. In the no blowing case, the variation of the correlation coefficient is in good agreement with the measurements of Klebanoff (1968). As the blowing parameter increases, the curve $R_{u^{\prime} v^{\prime}}=f(y)$ narrows, keeping its minimum value $R_{u^{\prime} v^{\prime}}=-0.42$ constant. 


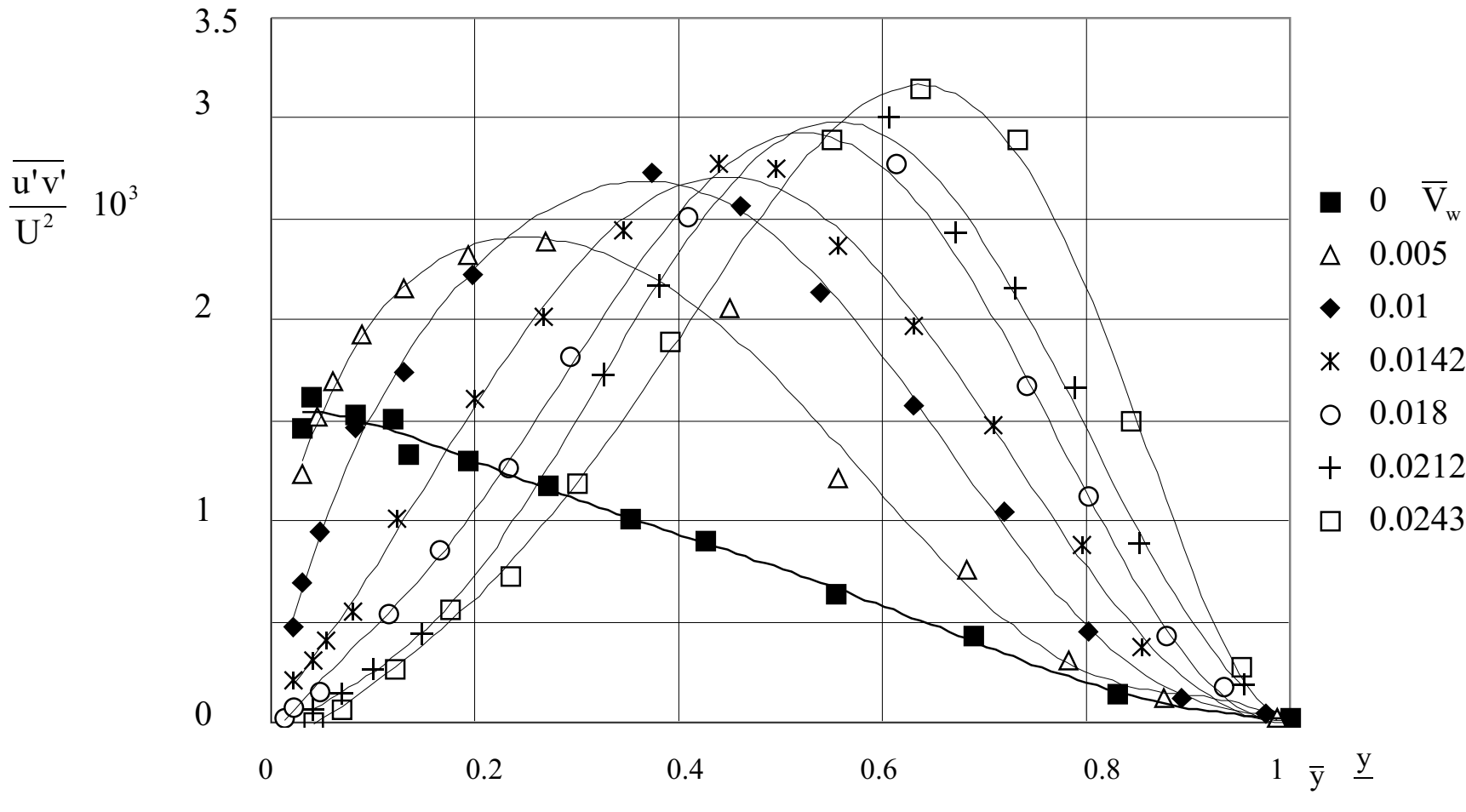

Figure 9. Turbulent stresses distribution in the boundary layer at $x=700 \mathrm{~mm}$ (same legend as in Fig. 5).
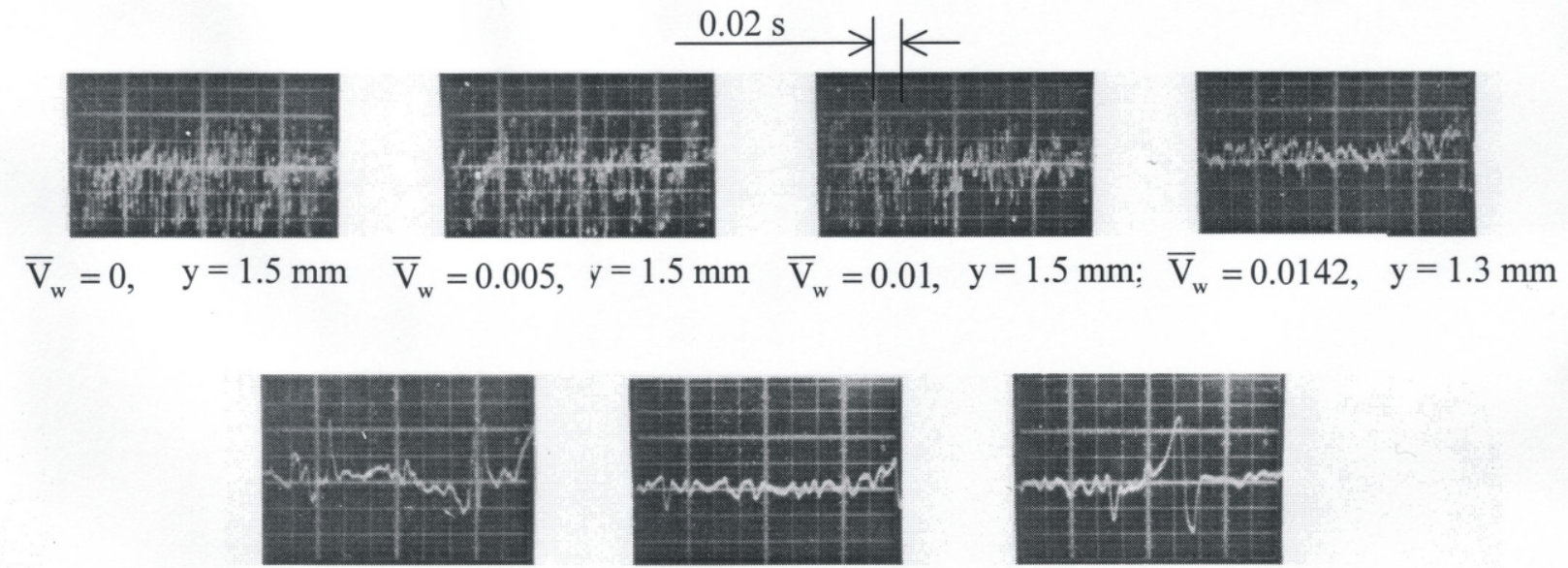

$\overline{\mathrm{V}}_{\mathrm{w}}=0.018, \quad \mathrm{y}=1.1 \mathrm{~mm}$

$\overline{\mathrm{V}}_{\mathrm{w}}=0.0212, \quad \mathrm{y}=1 \mathrm{~mm}$

$\overline{\mathrm{V}}_{\mathrm{w}}=0.0243, \quad \mathrm{y}=1 \mathrm{~mm}$

Figure 10. Oscillograms of the velocity turbulent components instantaneous product for different values of the blowing parameter at $\mathrm{x}=700 \mathrm{~mm}$.

The measured data treatment of the correlation coefficient showed that its variation, for all investigated values of the blowing parameter in the present work, depends only on one parameter, which is the dimensionless horizontal velocity $\bar{U}$. In Figure 8, it is shown the measured values of the correlation coefficient as a function of the dimensionless horizontal velocity, $\bar{U}$, i.e., $R_{u^{\prime} v^{\prime}}=f(\bar{U})$. It is shown that the correlation coefficient varies only as a function of the dimensionless velocity $\bar{U}$, and the blowing velocity almost caused no influence on the distribution of the correlation coefficient in the boundary layer.

Traditionally, graphs of the turbulent stresses distribution in the boundary layer are presented as functions of the dimensionless vertical coordinate, since $\overline{u^{\prime} v^{\prime}}=f(\bar{y})$, where $\bar{y}=\frac{y}{\delta}$. In such coordinates, at the wall and outside the boundary layer, the turbulent stresses are zero.

Once the numerical values of the intensities of the velocity turbulent components $\frac{\sqrt{\overline{u^{\prime 2}}}}{U_{\infty}}=f(\bar{y})$
$\frac{\sqrt{v^{\prime 2}}}{U_{\infty}}=f(\bar{y})$ and, and the distribution of the correlation coefficient in the boundary layer, $R_{u^{\prime} v^{\prime}}=f(\bar{y})$, are known, the instantaneous product $\frac{\overline{u^{\prime} v^{\prime}}}{U_{\infty}^{2}}=R_{u^{\prime} v^{\prime}} \frac{\sqrt{\overline{u^{\prime 2}}}}{U_{\infty}} \frac{\sqrt{\overline{v^{\prime 2}}}}{U_{\infty}}$, which is directly proportional to the turbulent stresses. The results of those calculations are graphically presented in Fig. 9.

In the no blowing conditions, the maximum of the turbulent stresses is sharp and located near the wall, in the 
turbulent nucleus of the boundary layer. As the blowing increases, the turbulent stresses maximum increases and shifts away from the wall. Besides that effect, the turbulent stresses maximum smoothens. In the present work, at the highest blowing parameter value $\bar{V}_{w}=0.0243$, the turbulent stresses values increased more than twice.

In Figure 10, oscillograms of the instantaneous product of the horizontal and vertical turbulent components, $\mathrm{u}^{\prime} \mathrm{v}^{\prime}$, are presented, determined as described in the paragraph before Eq. (9). The oscillograms were recorded for all values of the blowing parameter and at the position of the X-shaped transducer 55A38, closest to the wall. The oscillograms show that as the blowing velocity increases, the amplitude of the pulsations product decreases, and the pulsations characteristic frequency also decreases. For large values of the blowing parameter $\left(\bar{V}_{w}=0.018,0.0212\right.$ and 0.0243$)$, it is seen that on the background of low amplitudes of the pulsations frequencies, non-stationary abrupt jumps appear in the pulsations, u' v' Such phenomena are caused by the turbulence intermittency in the viscous sub-layer, where $\overline{u^{\prime} v^{\prime}} \max$ is the turbulent stresses maximum value when there is blowing, and $\overline{u^{\prime} v^{\prime}} \max 0$ the non blowing turbulent stresses maximum value.

$\frac{\text { The }}{u_{t}^{\prime} v^{\prime}}$
$\overline{u^{\prime} v_{\max }^{\prime}}$ . The analysis of the measured data of the turbulent characteristics of the boundary layer, particularly the relative turbulent stresses, showed that the more appropriate coordinate is the relative velocity $\overline{\mathrm{U}}$, instead of $\overline{\mathrm{y}}$. Figure 5 shows the $\bar{\tau}_{t}=f(\bar{U})$ distribution, which has a general shape for all blowing intensities.

The relative turbulent stresses maximum corresponds to $\bar{U}=2 / 3$. In the same figure several other data are plotted together with the results of this study: Tani (1969)-permeable porous sheet;Kont Bello(1968)-plane jets.

In this paper, in the non-blowing boundary layer it was not possible to measure turbulent stresses near the wall, where $\bar{U}<0.6$. However, under blowing, a possibility of measuring lower velocities appeared. It is important to note that with a blowing increase, the turbulent stresses values measured kept the general trend until horizontal velocities close to zero. This discovery may be used to propose new semi-empiric methods of turbulent boundary layer calculation and also for numerical simulations.

The tendency curve was adjusted from the experimental data in the form of a 4 th order polynomial as follows

$\bar{\tau}_{t}=\frac{\overline{u^{\prime} v^{\prime}}}{\overline{u^{\prime} v_{\max }^{\prime}}}=f(\bar{U})=a+b \bar{U}+c \bar{U}^{2}+d \bar{U}^{3}+e \bar{U}^{4}$

To find the coefficients $a, b, c, d$ and e for the tendency curve, the following conditions were used:

for $\overline{\mathrm{U}}=0, \mathrm{f}(\overline{\mathrm{U}})=0$ and

$\mathrm{f}^{\prime}(\overline{\mathrm{U}})=0$

for $\overline{\mathrm{U}}=1, \mathrm{f}(\overline{\mathrm{U}})=0$

for $\overline{\mathrm{U}}=2 / 3, \mathrm{f}(\overline{\mathrm{U}})=1$ and

$\mathrm{f}^{\prime}(\overline{\mathrm{U}})=0$

Under such conditions, Eq. (10) becomes

$$
\bar{\tau}_{t}=f(\bar{U})=\frac{27}{4} \bar{U}^{2}(1-\bar{U})
$$

Figure 11 demonstrates that the tendency curve established by Eq. (12) shows excellent agreement with the measured data.

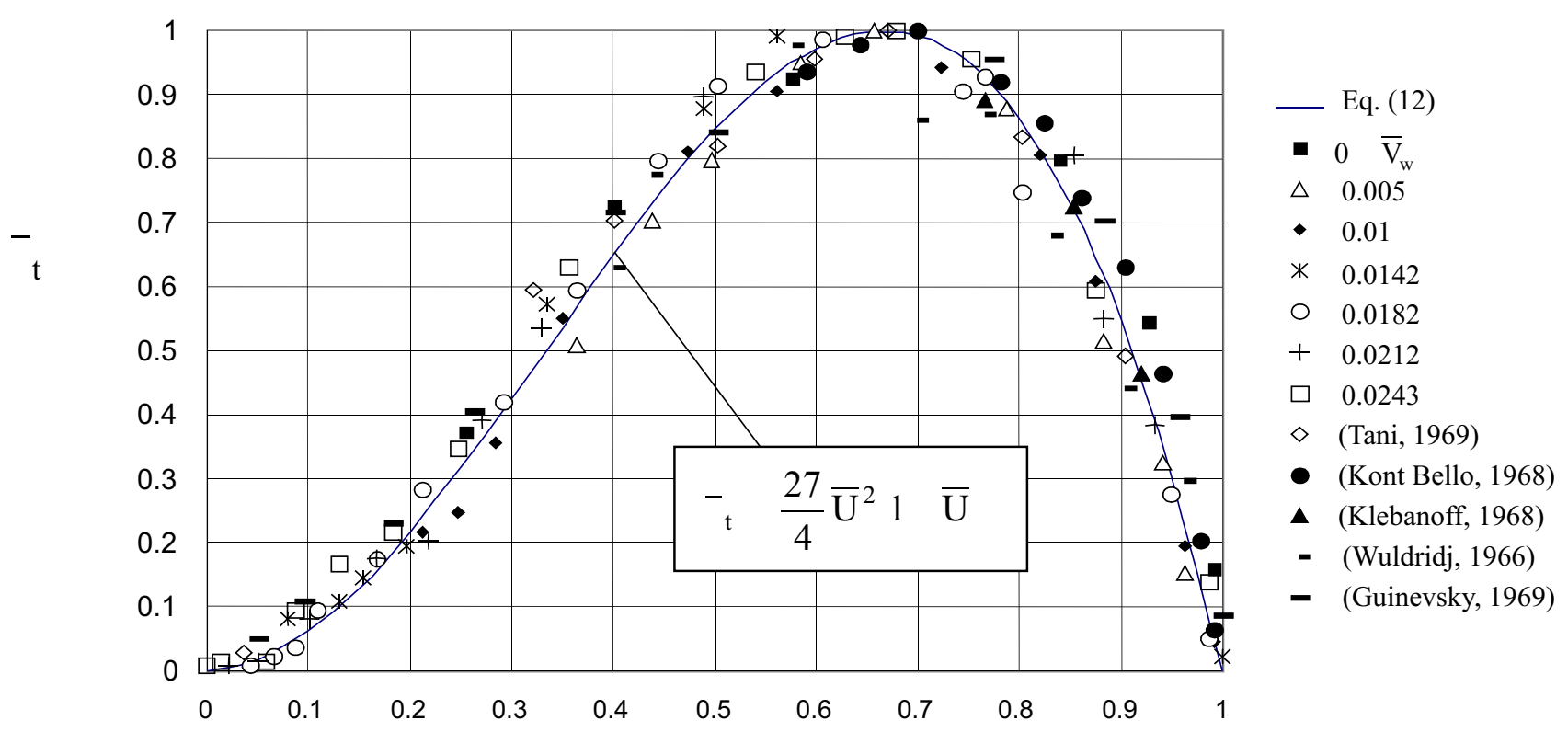

Figure 11. The relative turbulent stresses in the boundary layer with respect to relative velocity at $\mathrm{x}=700 \mathrm{~mm}$. 

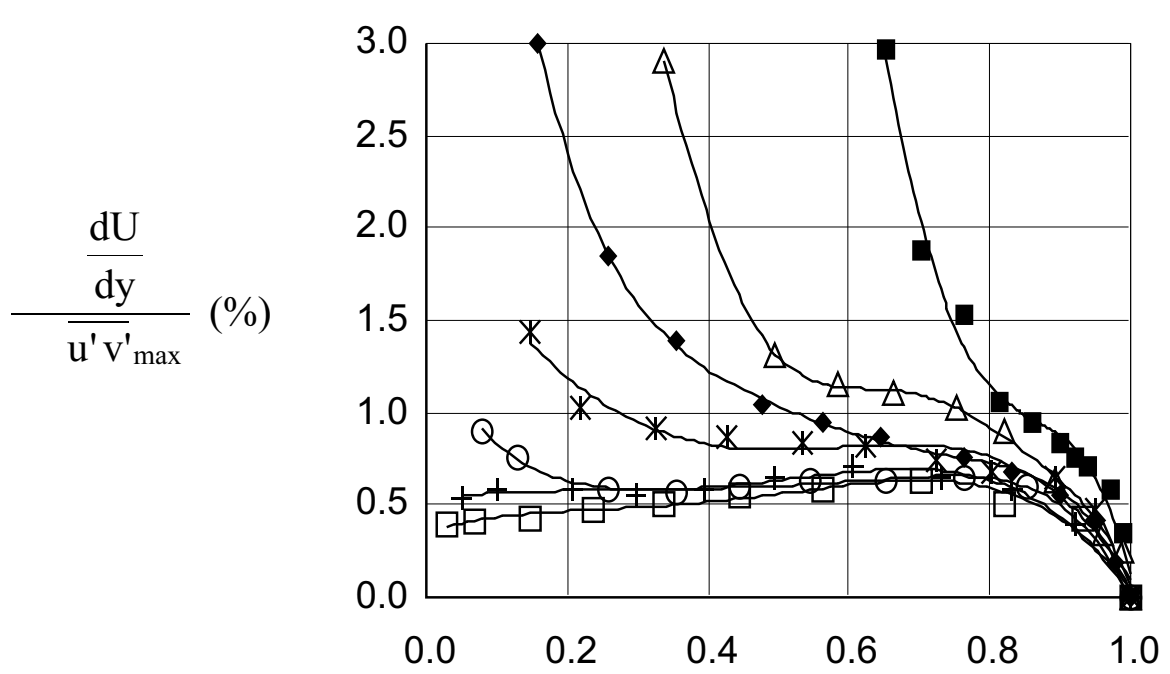

$0=\overline{\mathrm{V}}_{\mathrm{w}}$

$\triangle 0.005$

$\bullet 0.01$

* 0.0142

O 0.018

$+0.0212$

0.0243

$\overline{\mathrm{U}}$

Figure 13. Comparison between viscous and turbulent stresses for several values of the blowing velocity at $\mathrm{x}=700 \mathrm{~mm}$.

\section{CONCLUSION}

In this study, a theoretical and experimental analysis has been carried out to predict turbulent stress distribution in the turbulent boundary layer on a permeable porous plate. The review of the literature shows that severalhypotheses are considered that generally set a correlation between the Reynolds' turbulent stresses and average horizontal velocity on the boundary layer, but among hundreds of hypotheses, it has not been found a general one that would fit to the whole boundary layer, and therefore the turbulent stresses' "behavior" towards the wall is yet to be defined.

Two objectives have been achieved with the present work: (i) a general analytic correlation between relative turbulent stresses and relative horizontal velocity was established, and (ii) Based on this correlation, a flow model for turbulent boundary layer on permeable porous plane was introduced and it was demonstrated that under high blowing intensities, the velocity profile approaches the velocity profile in plane jet flow.

The chief contribution of the work presented in this paper is that it focuses attention on the results of analytic correlations derived from original experimental data for future scientific and industrial applications. The dimensionless results obtained for the porous wall averaged turbulent stresses and velocity profiles could be applied extensively once the physical and operating parameters of the specific process under consideration are known.

\section{REFERENCES}

Antonia, R. A. and Zhu, Y., 1995. Effect of concentrated wall suction on a turbulent boundary layer, Phys. Fluids 7, 2465.

Bataille, F., Younis, B. A., Bellettre, J., and Lallemand, A., 2003. Prediction of turbulent heat transfer with surface blowing using a non-linear algebraic heat flux model, Int. J. Heat Fluid Flow 24 (5), 680-684.

Bellettre, J., Bataille, F. and Lallemand, A., 1997. A study of a turbulent boundary layer with injection, in: ASME fluids Engineering division summer meeting, Symposium on separated and complex flows, Vancouver,
Canada, 8 p.

Bellettre, J., Bataille, F. and Lallemand, A., 1999a. A new approach for the study of turbulent boundary layers with blowing, Int. J. Heat Mass Transfer 42 (15), 29052920.

Bellettre, J., Bataille, F. and Lallemand, A., 1999b. Prediction of thermal protection of walls by blowing with different fluids, Int. J. Therm. Sci. 38, 492-500.

Bellettre, J., Bataille, F., Rodet, J. C. and Lallemand, A., 2000. Thermal behavior of porous plates subjected to air blowing, Journal of Thermophysics and Heat Transfer 14 (4), 523-532.

Bushnell, D. M. and Hefner, J. N. (Eds.), 1990. Viscous drag reduction in boundary layers, Progress in Astronautics and Aeronautics 123, American Institute of Aeronautics and Astronautics, Washington.

El-Hady, N. M., 1991. Effect of suction on controlling the secondary instability of boundary layers, Phys. Fluids A3, 393.

Guinevsky, A. S., 1969. Turbulent Jets Theory, 1st Edition, Machines Construction, Moscow.

Hahn, S., Je, J. and Choi, H., 2002. Direct numerical simulation of turbulent channel flow with permeable walls, Journal of Fluid Mechanics 450, 259285.

Hinze, J. O., 1975. Turbulence (An introduction to its mechanism and theory), 2nd Edition, McGraw-Hill, New York.

Kays, W. M., 1972. Heat transfer to the transpirated turbulent boundary layer, Int. J. Heat Mass Tran. 15, 10231044.

Kont Bello, G., 1968. Turbulent Flow in Parallel Flow Channels, Mir, Moscou.

Klebanoff, P. S., 1955. Characteristics of turbulent boundary layers with zero pressure gradient, NACA Report, 1247.

Metzger, M. M., Klewicki, J. C., Bradshaw, K. L. and Sadr, R., 2001. Scaling the near-wall axial turbulent stress in the zero pressure gradient boundary layer, Physics ofFluids 13(6), 1819-1821.

Polyakov, A. F., Reviznikov, D. L., Shen, Q., Tang, J. R. and Wei, S. R., 2001. Conjugate model for heat and mass transfer of porous wall in the high temperature gas flow, Acta Mechanica Sinica 17 (3), 245-250. 


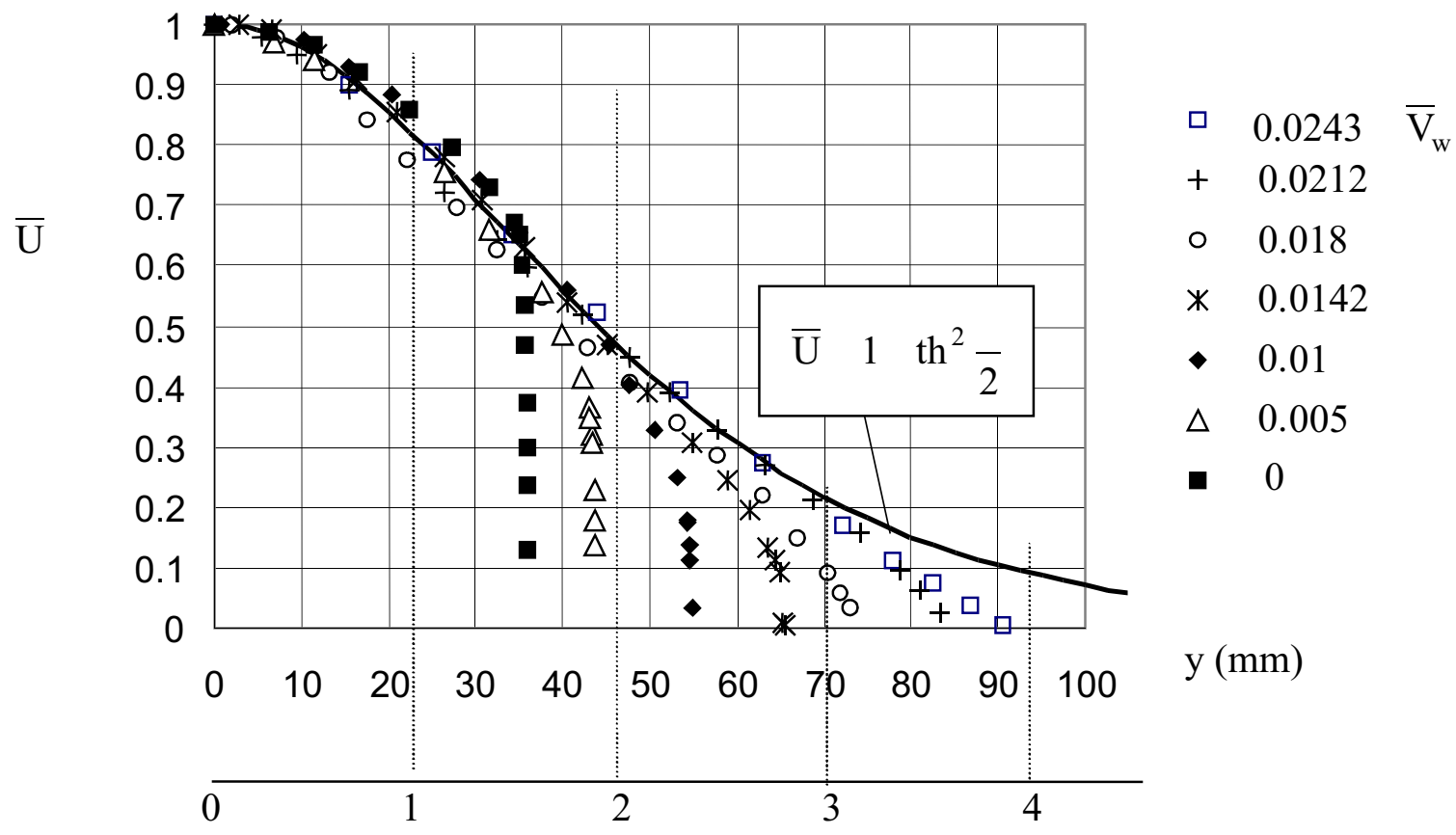

Figure 12 . The dimensionless horizontal velocity in the boundary layer with respect to $\mathrm{y}$ and $\zeta$ at $\mathrm{x}=700 \mathrm{~mm}$.

\section{Turbulent boundary layer on permeable porous plate formation patterns}

The analysis of the experimental data in the turbulent layer velocity distribution reveals the fact that the flow outside the boundary layer does not depend on the observed phenomena on the wall and develops according to its own rules. It is interesting to match the external parts of the horizontal velocity profiles. This is possible to be done by building the velocity profiles not from the wall, as shown in Fig. 4, but from the profiles external parts, as shown in Fig. 12.

One can observe that all profiles are coincidentwithin the horizontal relative velocity range $2 / 3<\mathrm{U}<\overline{1}$. This range of the velocity profile corresponds to the turbulent stresses descending interval (Fig. 11). Increasing the blowing, the velocity profiles become more coincident in the highest $\mathrm{U}$ variation range. It is logic to suppose there is an asymptotic profile that corresponds to the highest value of the blowing parameter. This profile can be determined under the assumption that as blowing increases the laminar stresses become negligible in presence of turbulent stresses.

Such assumption has a solid basis. In Figure 13, it is shown a comparison between viscous and turbulent stresses for several blowing parameters.

On the wall surface with no blowing, the viscous stresses $\tau_{v}=\mu \frac{d U}{d y}$ have a maximum value and the turbulent

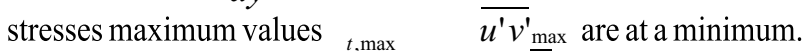
For this reason, the corresponding curve $\bar{V}_{w}=0$ abruptly goes up. The viscous stresses were determined from the velocity profiles directly in the viscous sub-layer with the methodology presented in section 3. The blowing reduces the horizontal velocity gradient in the boundary layer and because of that, the ratio $\frac{\tau_{v}}{\tau_{t}}$ value also decreases, and for $\bar{U}>2 / 3$ the viscous stresses are lower than $3 \%$ of the maximum turbulent stresses. A blowing increase decreases abruptly the viscous stresses and when the blowing parameter is
$\bar{V}_{w}>0.018$ they do not reach, even at the wall, $1 \%$ of the maximum turbulent stresses. These observations validate the assumption that as blowing increases the laminar stresses become negligible in presence of turbulent stresses throughout the boundary layer.

To find out the velocity profile analytic expression for high blowing parameter values one may use the Prandtl's hypothesis for turbulent stresses:

$$
\tau_{t}=\rho \ell^{2}\left(\frac{d U}{d y}\right)^{2}
$$

where $\ell$ is the mixed length.

Using the turbulent stresses distributions of Eq. (12), and equalizing the right sides of Eqs. (12) and (13), it is obtained

$$
\left(\frac{d \bar{U}}{d \bar{y}}\right)^{2}=A \bar{U}^{2}(1-\bar{U})
$$

where $A=\frac{27}{4} \frac{\delta^{2}}{\ell^{2}} \frac{\tau_{t, \max }}{\rho U_{\infty}^{2}}=$ constant.

After integration, it follows

$$
\bar{U}=1-t h^{2} \frac{\zeta}{2}
$$

where th is the hyperbolic tangent, and $\zeta=\sqrt{A}(1-\bar{y})$ the argument.

The graphic representation of Eq. (15) is also shown in Fig. 12. Equation (15) is known, in the gas dynamics science, as the velocity profile for plane jets.

From this analysis it results that under an increase of the blowing rate in the turbulent boundary layer, the horizontal velocity profile tends asymptotically to the plane jet velocity profile.

This result was also confirmed based on experimental data from turbulent plane jet measurements by Guinevsky (1969). 
Rodet, J. C., Campolina-Franca, G. A., Pagnier, P., Morel, P. and Lallemand, A., 1997, Etude en soufflerie thermique du refroidissement de parois poreuses par effusion de gaz, Rev. Gen. Therm., 37, 123-136.

Schlichting, H., 1960. Boundary Layer Theory, $4^{\text {th }}$ edition, McGraw-Hill, New York.

Schwarz, A. C., Plesniak, M. W. and Murthy S. N. B., 2002. Response of turbulent boundary layers to multiple strain rates, Journal of Fluid Mechanics 458, 333377.

Silva Freire, A. P., Cruz, D. O. A. and Pellegini, C. C., 1995, Velocity and temperature distributions in compressible turbulent boundary layers with heat and mass transfer, Int. J. Heat Mass Transfer 38 (13), 25072515.

Tani, I., 1969. Computation of Turbulent Boundary Layers, Vol.1, Conference Proceedings California.

Vilela-Mendes, R. and Dente, J. A., 1997. Boundary-layer control by electric fields: A feasibility study. arXiv: physics/9705020, 1, 15 May.

Vlassov, D., 2002. Skin friction on a plane porous plate (in Portuguese), II Brazilian National Congress of Mechanical Engineering ,João Pessoa, PB, Brazil.

Vlassov D. and Polyaev V., 1975. Using hot-wire probes for investigation of flow in the boundary layer along a permeable surface, DISA Information, Measurement and Analysis 18, 11-14.

Wuldridj, M., 1966. Rocket and Cosmonautic Technique, Mir, Moscow, 159-168. 